\title{
Entrelacs
}

Cinéma et audiovisuel

\section{La Machine}

\section{La plus belle harmonie}

\section{Didier Lambert}

\section{OpenEdition}

\section{Journals}

Édition électronique

URL : http://journals.openedition.org/entrelacs/147

DOI : $10.4000 /$ entrelacs. 147

ISSN : 2261-5482

\section{Éditeur}

Éditions Téraèdre

\section{Édition imprimée}

Date de publication : 1 novembre 2005

Pagination : 134-136

ISBN : 978-2-912868-70-1

ISSN : $1266-7188$

Référence électronique

Didier Lambert, «La plus belle harmonie », Entrelacs [En ligne], 5 | 2005, mis en ligne le 01 août 2012, consulté le 22 avril 2019. URL : http://journals.openedition.org/entrelacs/147 ; DOI : 10.4000/ entrelacs. 147

Ce document a été généré automatiquement le 22 avril 2019

Tous droits réservés 


\section{La plus belle harmonie}

\section{Didier Lambert}

1 Si la représentation de l'homme et de la machine a été la clef de voûte de l'âge d'or du cinéma (de L'arrivée d'un train en gare de La Ciotat aux Temps modernes ou de L'arroseur arrosé à Métropolis) il y a beau temps que la machine a disparu des scénarios.

2 La représentation à l'écran du monde du travail industriel et de l'esclavage ouvrier a suivi une courbe continuellement descendante alors même qu'une toute autre mécanique allait peu à peu la supplanter : la « machine humaine » et ses rouages innombrables, autrement photogéniques - il faut le penser - que la «Lison» de Jacques Lantier ou que la porte électrique du garage de Monsieur Hulot. Mais n'était-ce pas se perdre avant que s'être trouvé ? Car en subissant cette transmutation le cinéma a rompu un des liens essentiels qui l'enracinait à l'aventure même de l'homme. Aujourd'hui la dimension politique du héros ne se lit plus aussi simplement qu'hier dans son seul rapport à la machine - objet phare de son statut social - (et ceci quelqu'en eut été son mode de représentation) mais dans l'énonciation sophistiquée de ses névroses.

3 Les héros de cinéma n'étant plus aussi souvent représentés sur leurs lieux de travail, ils semblent en avoir perdu peu à peu et le goût et le besoin. Certes nos héros sont toujours tributaires d'une situation économique donnée, d'une identité professionnelle consubstantielle à leur état d'hommes et de femmes mais la machine ne rencontrant plus la main de l'acteur se voit réduite à une simple figuration bien insuffisante pour le représenter et le circonscrire à un système de classe. Aujourd'hui la machine nous est montrée (ou plus exactement son absence nous est dite) comme totalement maitrisée, disciplinée, en un mot absorbée. Ses représentations ne sont plus jamais directement politisées ni filmées comme une partie documentaire ou vériste. Au contraire, intégrées dans le récit dans le seul but de permettre un décor nouveau, un rebondissement plus ou moins justifié mis là pour dépayser le spectateur elles semblent participer d'une gigantesque appropriation universelle. Cependant la machine «monstre froid» contre laquelle l'homme se bat depuis l'aube de l'humanité est toujours là, transmuée dans ses figures et ses métaphores.

«Étre moderne, c'est bricoler dans l'incurable »

Cioran 


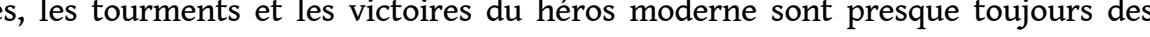
constructions abstraites d'ordre personnel, intime et combien peu d'entre eux le réconcilient avec un groupe, une communauté, une société. Au terme de la démonstration dialectique que constitue « l'aventure » d'un récit fictionnel nous percevons à quel point notre héros ne maîtrise pas grand chose et que l'incurable est à notre porte. En nous désignant à toute force comme ce nouveau conquistador prétendument vainqueur à la fois de la haute technologie et de la matière (qu'est ce que l'ADN au cinéma si ce n'est le nouveau Graal ?) nous nous coupons chaque jour davantage de notre rapport au monde réel, à la nature, à la vie. Le héros de cinéma est devenu un psychologue, un enquêteur (journaliste ou avocat d'affaires) un super limier un profiler investiguant sur un sujet chaque jour plus insaisissable, virtuel ; luttant contre un ennemi invisible, tentaculaire, en un mot chimérique. Cette extraordinaire prééminence de la psychologie ne fait qu'éloigner les personnages d'un rapport affectif à l'objet. Hier la machine n'aliénait que le temps et son corollaire romantique - la liberté. Quel bonheur, quel espace lorsque les machines enfin tues et le rideau de fer baissé les personnages re- goûtaient chaque soir et chaque fin de semaine aux délices de la "vraie» vie. Souvenons-nous des héros de Becker. L'espace restant en dehors de l'usine et de l'atelier relevait vraiment de l'aventure ; on perdait un billet de loterie et les péripéties pour le retrouver faisaient de la vie un monde inconnu, hostile, dangereux où les traumatismes, les blessures et plus encore les moments heureux vous marquaient pour toujours.

De plain-pied avec la tragédie de son histoire le héros toujours plus ou moins en rupture momentanée de mécanisation affrontait la vie avec une innocence qu'il a - sinon tout à fait perdue - tout au moins reléguée dans un patrimoine qui ne le concerne plus. De fait jamais notre cinéma conquérant n'a été si loin de l'idée d'anarchie, de désaliénation, de libération. Précisément parce que ses héros prétendent être maîtres de leur destinée. Cependant, aliénés à la psychologie de masse et au discours triomphant qui la sous-tend ils ne débattent plus que de conflits sexuels et policiers. Ils s'embourbent lourdement, avec une fade complaisance, dans un espace libidinal jadis domaine réservé de la littérature. Devenus des « machines à paroles » nos héros subissent de violentes thérapies de groupe souvent plus spectaculaires qu'efficaces dans lesquels chacun d'entre eux, selon la combinatoire choisie par les auteurs, jouera au deus ex machina - innombrables variations interchangeables sur les thèmes inépuisables de la machina psychologica (sexualité, vie de couple, adultères, éducations des enfants, maladie, accidents) - mais surtout, partout, la même peur du silence.

6 Hier, trop bruyante, la machine empêchait de parler ou de s'interpeller d'une chaîne à l'autre, aujourd'hui chaque jour plus silencieuse elle ne peut plus espérer intéresser la forme d'expression la moins discrète, la plus tonitruante, peuplée d'humains ou d'humanoïdes dévastateurs.

7 Etranger à la contemplation (l'écueil de l'ennui en est si proche à l'écran) le héros de cinéma parle sans arrêt. Il s'épanche, se répand en humeurs et en déclarations égotistes. Ses pannes, ses ratés, ses défaillances ne viennent pourtant que d'un mauvais usage, d'un réglage défectueux, d'une mauvaise application des possibilités de la mécanique interne. Nos héros se souvenant peut-être encore d'un lointain passé ouvrier en retrouvent soudain le jargon alors ils nous « pètent un câble » ou nous « grillent un fusible ».

De fait, se servir de la machine a toujours eu un rapport plus ou moins direct à la servitude, et le cinéma - plus que jamais moyen d'évasion - en a peut être trop 
complaisamment montré les seuls aspects aliénants. L'ouvrier d'usine plein de cambouis, le garagiste, le conducteur de loco, le petit imprimeur ne sont plus les personnages qui font avancer l'intrigue, ce ne sont plus que des comparses chargés - quelques minutes de représenter l'humanité laborieuse de laquelle à toute force le héros tente de s'éjecter. Le rapport à l'artisanat, apanage des retraités, des marginaux et des terroirs ensoleillés avait une vertu plus apaisante, plus exotique.

De plus, travailler sur la machine exige souvent un lieu et un personnage fixes peu compatibles avec l'idée de mouvement propre au cinéma. Alors, comme le héros a toujours besoin de se battre contre quelque chose, ses causes sont devenues abstraites, et sa longue quête peu à peu devenue enquête. En s'éloignant irrémédiablement de la fixité et de la contemplation il est entré dans un nouvel ordre de chocs et de perceptions. Ce qu'il fuit aussi délibérément a fini par être un mal invisible, une super machine sans âme pouvant lui coûter la vie. Les circonvolutions de ce nouveau surmoi sont infinies, d'un raffinement illimité et leur énonciation - plus encore que leur exploration - constitue la trame même du film moderne. Le policier de L'humanité de Bruno Dumont est à mes yeux la personnification et le rejet de cette nouvelle et curieuse machine, mi-homme, mi-robot, homme mécanique en somme, téléguidé tant dans sa compassion que dans l'exercice de sa profession, il réunit douloureusement ces deux positions inconciliables : compatir / châtier.

Négation de tout un cinéma psychologique à contre courant de toutes les postures convenues, intégrant délibérément les alibis d'un certain cinéma vérité (acteurs non professionnels, décors réels, dialogues exempts de tout didactisme, représentation de la souffrance (pour ne pas dire de la misère) mais sans le discours sur la souffrance etc. Combien d'autres films même d'apparence moins squelettique dans leur économie de filmage ont mis à jour la même thématique inconciliable entre la liberté de pensée et la liberté d'agir ? Laissant trop souvent un sentiment de totale gratuité, d'irréalité à force de verbiage et de joutes intellectuelles, trop d'œuvres modernes manquent leur but: traduire un espace de guerre et donner à s'exprimer deux postulations contradictoires.

11 En gagnant de l'espace et du temps le héros d'aujourd'hui ressent plus tragiquement son rapport au monde, et, éternel belligérant sans adversaire véritable il s'épuise en pure perte. Toutefois je me souviens d'une œuvre qui démontait absolument et admirablement cette ambiguïté ; tout à la fois peinture et leçon de maturité de ses deux personnages elle nous dressait d'entrée de jeu le bilan d'une situation d'écrasement et du lent pourrissement qui avait éloigné un père de sa fille (difficulté de choisir une position sociale, incommunicabilité de parler et de partager, poids de tout un machinisme social et au bout de la route l'effort accompli pour s'en défaire).

12 En refaisant le long de cette voie ferrée le chemin à l'envers, ils remontaient à la source de leurs conflits. C'est le miracle du film d'Alain Cavalier Un étrange voyage. Si j'évoque pour conclure ce film admirable, c'est qu'il me paraît illustrer parfaitement un processus de désaliénation réussi par la volonté conjuguée de ses deux protagonistes. A la fin ces deux êtres sont libres et libérés - c'est à dire conscients des véritables enjeux de la vie et de ses contraintes et enfin soudés pour y faire face. Réussite parfaite en ceci qu'il ne s'agit pas d'un discours sur les innombrables aliénations modernes mais d'une œuvre qui prends le temps de les regarder, de les révéler, de les démonter pour - finalement - s'en écarter à distance respectable, enfin viable.

13 C'est à ma connaissance l'un des films les plus harmonieux et les plus pacifiants. «Avec toutes les dissonances construire la plus belle harmonie ». C'était déjà la devise d'Héraclite 


\section{AUTEUR}

DIDIER LAMBERT

Étudiant à l'ESAV 